\title{
ANÁLISE DA EDUCAÇÃO EM DIREITOS HUMANOS, VALORES E CIDADANIA NA FRONTEIRA TRINACIONAL A PARTIR DA PERCEPÇÃO DOCENTE
}

DOI: $10.48075 /$ ri.v24i1.25787

Mateus Silva de Meneses ${ }^{1}$ Miguel Ahumada Cristi ${ }^{2}$

RESUMO: O artigo a seguir é resultado de uma pesquisa teórica e de um estudo de campo sobre a denominada Educação em Direitos Humanos, principalmente, mas também incluindo as ideias de valores e cidadania. É uma investigação, a partir de entrevistas, sobre como os conteúdos desta esfera da educação são acolhidos pelos professores do Ensino Fundamental II que lecionam nas escolas da Fronteira Trinacional entre Brasil, Argentina e Paraguai. Primeiramente, apresentamos uma fundamentação teórica desses direitos. Logo, tratamos dos princípios da educação em direitos humanos, estabelecidos por um programa de nível global da ONU, e finalizamos a sessão teórica com um panorama geral da situação da educação em direitos humanos na América Latina. Na segunda parte do texto apresentamos a análise dos dados surgidos das entrevistas aplicadas, e que articulamos sob a luz dos conceitos trabalhados na parte teórica, em busca de seus significados mais profundos.

\section{ANALYSIS OF HUMAN RIGHTS EDUCATION, VALUES AND CITIZENSHIP IN THE TRI-NATIONAL BORDER FROM THE TEACHERS PERCEPTION}

ABSTRAC: This article is the result of theoretical research and empirical study about Education in Human Rights, mainly, but also including the ideas of values and citizenship. It is an investigation, based on interviews, on how the contents of this sphere of education are received by the teachers of Elementary School II who teach in the schools of the Trinational Border between Brazil, Argentina and Paraguay. First, we present a theoretical basis for these rights. Therefore, we address the

\footnotetext{
${ }^{1}$ Graduando em Filosofia na UNILA. E-mail: mateusmenesescontato@gmail.com

2 Licenciado em Educação e Pedagogia pela Universidad Nacional Arturo Prat, Iquique, Chile; Mestre em Filosofia pela Universidad Jesuita Alberto Hurtado, Santiago de Chile; Doutor em Educação e Sociedade pela Universitat de Barcelona, Catalunya. Desde 2015 ministra aulas de Espanhol no Ciclo Básico de Estudos, História da Educação e Filosofia da Educação nos eixos de formação pedagógica das licenciaturas, na Universidade Federal da Integração Latino-Americana (UNILA), Paraná, Brasil. Email: miguel.cristi@unila.edu.br
} 
principles of human rights education, established by a global UN program, and we conclude the theoretical session with an overview of the situation of human rights education in Latin America. In the second part of the text, we present the analysis of the data arising from the applied interviews, which we articulate with concepts worked on in the theoretical part, in search of their deeper meanings.

Key Words: Human Rights, Education, Tri-national Border.

\section{INTRODUÇÃO}

Este artigo é resultado de uma pesquisa que tinha o intuito de conhecer e compreender, em termos gerais, de que maneira, e a partir de quais fundamentos, as escolas públicas da região da Fronteira Trinacional (Brasil, Paraguai e Argentina), promovem uma educação voltada à formação em Direitos Humanos, valores e cidadania ${ }^{3}$.

Para concretizar tais objetivos, dividimos a pesquisa em dois momentos. No primeiro, realizamos um estudo sobre a teoria que aborda a temática a partir da leitura de textos de pesquisadores cujo foco é a educação em direitos humanos, além de analisar documentos como a Declaração Universal dos Direitos Humanos e a Declaração dos Direitos da Criança. Em seguida, a partir da leitura do Programa Mundial de Educação em Direitos Humanos, procuramos compreender de forma mais precisa essa esfera da educação e as propostas pedagógicas para sua aplicação nos sistemas escolares. Finalmente, para aproximar o estudo à nossa realidade, fizemos uma análise da situação na América Latina desde vários ângulos: o relativo ao legislativo, ao currículo, à análise de materiais didáticos e possibilidades da formação de professores/as. O resultado desta etapa cumpriu uma função importante na elaboração deste artigo, no sentido de fornecer parâmetro para a compreensão da temática que pesquisou-se no campo.

Em um segundo momento, e com o objetivo de conhecer a situação da Educação em Direitos Humanos, valores e cidadania na Fronteira Trinacional, planejamos um estudo de campo. Este consistiu na aplicação de entrevistas, in loco, a docentes das redes públicas de ensino das cidades de Foz do Iguaçu, Ciudad del Este e Puerto Iguazu, para compreender o contexto real, o cenário prático destes conceitos, a partir das percepções dos docentes. Os resultados obtidos a partir desta pesquisa foram analisados de maneira descritiva e em articulação com a teoria que envolve a temática.

\footnotetext{
${ }^{3}$ A pesquisa foi desenvolvida no contexto do Grupo de Estudos em Educação em Direitos Humanos, Valores e Cidadania da UNILA, do qual formamos parte, e a partir das atividades de iniciação científica que se desdobraram daí.
} 
Em síntese, o artigo aborda a teoria geral dos direitos humanos e no âmbito específico da educação e, para aproximarmos à questão regional, apresentamos um panorama dos avanços em matéria de educação em Direitos Humanos na América Latina. Na segunda parte, apresentamos os dados da pesquisa de campo em articulação com a teoria desenvolvida. Esperamos que o resultado favoreça a compreensão do cenário da Educação em Direitos Humanos, valores e cidadania na região fronteiriça.

\section{SOBRE OS DIREITOS HUMANOS}

Um dos tantos caminhos possíveis para entender o que são os Direitos Humanos é o campo da Filosofia. Optamos, então, por analisar estes direitos desde um olhar filosófico.

Para adentrarmos nesta seara, é válido começar pela ideia do ser humano como relativamente ser para si, consciente de si próprio; isto é, como um ser consciente de sua existência no mundo (MILLAS, 1982). E porque esse mundo se apresenta de distintas maneiras ou realidades, produto justamente da atuação humana, as realidades humanas não estão dadas, mas são indeterminadas e, de igual forma que nossa existência, estão em permanente construção. Essa ideia da construção humana se caracteriza pela projeção e criação, o que implica expressão de intencionalidade no seu atuar (PEÑAILILLO, 2009, p. 304). Cabe destacar, neste ponto, que além do ser humano ter consciência de si, o mundo se Ihe apresenta constituído com a presença do outro e as colaborações e distensões que daí decorre. É precisamente da consciência dessa alteridade e sua legitimação que surgem os valores, princípios e regras morais que viriam a cumprir um papel de regulador da consciência e da atuação.

O anterior também nos leva a pensar, entre outras coisas, que a intencionalidade humana permite ao ser humano vislumbrar e projetar o ideal, entendendo isto, em termos kantianos, como dever ser intrínseco à realidade humana. Uma ação, segundo Kant, tem conteúdo moral quando praticada por dever e não por inclinação imediata, medo ou coerção (KANT, 2011, p. 28). Disse Kant “Uma ação praticada por dever tem o seu valor moral, não no propósito que com ela se quer atingir, mas na máxima que a determina; não depende, portanto, da realidade do objeto da ação, mas somente do princípio do querer (2011, p. 31)"

Projetar é isso, é lançar-se no imaginário e construção de uma ideia de mundo que ainda não é. Esse ideal, posto na condição de dever ser, constituem os valores e princípios 
orientadores da experiência, das formas de vida e de convivência (PEÑAILILLO, 2009, p. 305). Os valores morais, por sua vez, são uma das bases dos reguladores e parâmetros éticos. Assim também, na linha kantiana, que permeia parte da fundamentação dos direitos humanos, a moral constitui um dever ser. Trata-se de um dever ser onde a equação tu-eu é posta em prática. Onde, como aponta Peñailillo, "el prójimo aparece considerado análogamente a lo que es uno", e essa legitimidade que se atribui ao "outro" é que constitui o seu direito (PEÑAILILLO, 2009, p. 308).

Essa importância da pessoa humana tem, portanto, a contribuição da ética de Kant, que determina constituir o ser humano um "fim em si mesmo":

Em toda a criação tudo o que se queira e sobre o que se exerça algum poder também pode ser usado simplesmente como meio; somente o homem, e com ele cada criatura racional, é fim em si mesmo. Ou seja, ele é o sujeito da lei moral, que é santa em virtude da autonomia de sua liberdade (KANT, apud, NODARI; SÍVERES, 2015, p. 274-275).

Que o ser humano seja fim em si mesmo significa, basicamente, que é sujeito de dignidade. Kant define esse conceito lançando mão da noção de valor intrínseco, acima de todo preço:

No reino dos fins tudo tem um preço ou uma dignidade. Quando uma coisa tem um preço, pode-se pôr em vez dela qualquer outra como equivalente; mas quando uma coisa está acima de todo o preço, e, portanto, não permite equivalente, então tem ela dignidade (KANT, 2011, p. 82).

Portanto, a partir da construção conceitual kantiana, podemos identificar essa noção central que interpela à dignidade da pessoa humana, seu respeito e promoção. Como apontam Nodari e Síveres (2015, p. 275), se trata, por fim, do respeito à capacidade humana de escolha racional. O fim em si mesmo de que trata Kant se preenche de conteúdo quando nos referimos à realização humana, o pleno desabrochar de seu ser, potencialidades e projeção indeterminada.

Desde outro ângulo, essa reivindicação da importância humana também se fundamenta em um parâmetro ético onde o prazer e a felicidade são mais desejáveis que a dor e o sofrimento. Assim, o ser humano importa porque ele é sensível ao sofrimento. De forma que, tanto a ética deontológica (de raiz em Kant) quanto a teleológica (de raiz em Aristóteles) oferecem contribuições para a constituição dos direitos humanos. Segundo Isaiah Berlin (2018), tanto os imperativos categóricos quanto a utilidade são justificações para resguardar a área de não interferência externa. Ou seja, o imperativo "age apenas 
segundo uma máxima que pode ser universalizada", e o princípio da utilidade, segundo "deve se agir em prol do prazer da maioria", são fórmulas e instrumentos que permitem alcançar a ação moral e a área da liberdade individual (BERLIN, 2018, p. 6). Esses dois fundamentos de correntes éticas opostas se diferenciam porque o primeiro busca o bem em si mesmo, enquanto o segundo se preocupa com o bem que é promovido no mundo, mas ambos funcionam como limitação do arbítrio de pessoas, grupos e instituições sobre os indivíduos.

Colocadas estas questões, devemos necessariamente perguntar: por que elas são relevantes? Qual é a importância dos direitos humanos e de sua concretização por meio da educação? Uma resposta satisfatória seria que o caráter social da importância da promoção concreta dos direitos humanos visa constituir uma sociedade composta por cidadãos "éticamente responsables que buscan el bien común (...)" (Peñailillo, 2009, p. 308). Bem comum é entendido como a equação tu-eu:

Os direitos humanos "[...] são fruto de nossas tentativas de gerar regras ou princípios que sirvam para compatibilizar e harmonizar nossos interesses mais básicos com os interesses de outros indivíduos, quer considerados isoladamente, quer em grupo" (DIAS, 2010, p. 268 apud NODARI; SÍVERES, 2015, p. 272).

Os direitos humanos constituem a tentativa de estabelecer um ponto pacífico nos conflitos de interesses que permeiam a sociedade humana. São um conjunto de condições que se pressupõem universais e de interesse de todos/as os/as que compõem a espécie humana, que objetivam o desenvolvimento integral de cada indivíduo. $\mathrm{E}$ isso é conditio sine qua non para a resolução de conflitos. Justamente porque os direitos humanos propõem um ambiente social de igualdade, em termos materiais e espirituais, o que permitiria a realização plena da democracia, a forma ideal de resolução dos conflitos. Se não fôssemos capazes de concordar em alguns princípios básicos para a regência da vida, os grupos provavelmente não existiriam.

Direitos do homem, democracia e paz são três momentos necessários do mesmo movimento histórico: sem direitos do homem reconhecidos e protegidos, não há democracia; sem democracia, não existem condições mínimas para a solução pacífica dos conflitos (BOBBIO, 2004, p. 1).

No mesmo sentido, a Declaração Universal dos Direitos Humanos começa seu preâmbulo estabelecendo essa mesma conexão entre direitos humanos e pacificação das sociedades, ao afirmar que "o reconhecimento da dignidade inerente a todos os membros 
da família humana e de seus direitos iguais e inalienáveis é o fundamento da liberdade, da justiça e da paz no mundo" (NAÇÕES UNIDAS, 2009, p. 2).

Um último aspecto importante que devemos compreender no que concerne aos direitos humanos é o histórico da sua ampla institucionalização no pós-guerra. Isto favorecerá compreender com maior amplitude os conceitos e ideias tratadas até aqui.

Em abril de 1945, na cidade de São Francisco, surge a Organização das Nações Unidas (ONU). Em 10 de dezembro de 1948 a Declaração Universal dos Direitos Humanos (DUDH) foi aprovada pela ONU. Esses fatos possuem íntima relação com os horrores da Segunda Grande Guerra. Os crimes de lesa humanidade surgem, entre várias causas, do nacionalismo de Estados que eram soberanos no âmbito da política internacional, isto é, que não possuíam nenhum intermediário na relação com os demais Estados e com os indivíduos de seu próprio território. Assim, nessa época os direitos humanos são propostos como o instrumento de pacificação das sociedades. Segundo Casado Filho (2012), tanto esses direitos quanto as organizações que os promoviam se tornaram a partir de 1948 o critério normativo na relação entre os Estados e Estados/indivíduos, sendo amplamente aceito pela maior parte dos países da orbe. A DUDH é o documento mais traduzido do mundo, é amplamente conhecido e serve como sustentáculo de uma Rede Internacional de Proteção aos Direitos Humanos. De fato, em 1994, 184 dos 191 países membros da ONU haviam aderido à declaração.

Essa institucionalização teve como consequência a promoção dos direitos humanos através da educação formal, uma das instituições sociais mais universais e abrangentes no mundo ocidental. Não obstante, além da abrangência, a escola permite a formação do sujeito, um dos elementos mais importantes na construção de uma cultura dos direitos humanos.

\section{A EDUCAÇÃO EM DIREITOS HUMANOS NA AMÉRICA LATINA}

Em 2004, a Oficina do Alto Comissionado das Nações Unidas para os Direitos Humanos e a UNESCO produziram e submeteram à Assembleia Geral da ONU o Programa Mundial de Educação em Direitos Humanos. Este programa busca promover: a interdependência e universalidade desses direitos; a valorização das diferenças; a análise de problemas como a pobreza, os conflitos e a discriminação; a instrumentalização das pessoas da capacidade de determinar suas necessidades relativas aos direitos humanos; os 
conhecimentos sobre os mecanismos de proteção destes; métodos pedagógicos participativos e a presença dos direitos humanos na vida cotidiana dos educandos (Nações Unidas, 2005, p. 6).

Para além destes princípios, o Programa também sugere orientações práticas para a aplicação de seus princípios. Assim, o processo educativo deve contemplar a transversalidade curricular, isto é, garantir que todos os momentos do processo educativo devem conduzir à aprendizagem dos direitos humanos. Esses direitos devem estar presentes no plano de ensino, materiais didáticos e ser considerados no horizonte dos métodos pedagógicos e da formação docente. Além disso, a prática dos direitos humanos deve fazer parte do cotidiano da escola e os estudantes devem participar da vida escolar. Neste ponto, precisamente, devemos nos perguntar: como esses princípios de caráter global são vertidos em práticas no contexto da América Latina? Da legislação à formação docente, trazemos um panorama geral da região.

A onda de ditaduras na América Latina, entre os anos 60 e 80, tardou significativamente o avanço desses direitos. Os regimes autoritários não somente atrasaram a implantação de políticas nesse sentido, mas foram inclusive autores de violações sistemáticas dos direitos humanos. Mortes, torturas, sequestros e prisões arbitrárias formam o teatro de horror que tomou conta do continente naquela etapa da história latinoamericana (FRAGA; MAHLKE, 2010, p. 99).

Nos anos 70, as ditaduras da região se juntam para reprimir movimentos de resistência aos regimes, aliança conhecida como Operação Condor (FRAGA, 2010, p. 96). Isto agravou a situação, pois os avanços dos direitos humanos na época ficaram apenas restritos à luta de valentes movimentos populares pelo fim das prisões políticas, torturas e assassinatos cometidos pelos governos.

Com a redemocratização dos países da região, já na segunda parte dos anos 80 , os direitos humanos voltam ao cenário político como balizadores necessários para a construção de novas sociedades, inspiradas no Estado Democrático de Direito. Ainda assim, mesmo com o fim dos regimes ditatoriais, apenas a partir dos anos 2000 verificam-se progressos significativos em matéria de educação em direitos humanos.

Assim, já na década de 90, os progressos da educação em direitos humanos foram escassos na América Latina. Tanto no que se refere às dimensões do currículo, da formação de professores e da planificação nacional do tema em um programa. O único progresso 
notável da região, com base no Informe Interamericano da Educação em Direitos Humanos, o IIDH, ocorreu no nível formal e legislativo (RODINO et al, 2016, p. 96-97).

O cenário do período compreendido entre 2000 e 2012 é bem mais promissor. As conquistas são representáveis através dos seguintes pontos (RODINO et al, 2016, p. 98): a menção da Educação em Direitos Humanos na legislação dos países, quando estes tratam de caracterizar as bases da educação; a ampliação do conceito de educação, abrangendo a educação em valores, em direitos e para a cidadania; a incorporação, pela legislação nacional, dos princípios da Educação em Direitos Humanos. A partir disso, departamentos e instâncias governamentais foram criadas para a promoção dos direitos humanos e a sua materialização nos sistemas escolares (RODINO et al, 2016, p. 99).

Mas se a educação em direitos humanos é uma exigência dos países, nos perguntamos se existe, para além de ser uma exigência formal, um movimento no sentido de tornar possível a concretização da lei, através do currículo, dos materiais didáticos, da metodologia desses materiais e da formação de professores. Com relação ao currículo, não se identificou, através do IIDH, nenhuma disciplina específica sobre os direitos humanos. Esses direitos são frequentemente abordados ou em alguma disciplina de ética ou de forma transversal. Porém, registrou-se um crescimento da presença dos temas dos direitos humanos nos graus primário e secundário do ensino (RODINO et al, 2016, p. 103). Aquele tema que recebe uma maior atenção dos currículos é o da igualdade e combate à discriminação.

Por outro lado, a presença destes direitos na legislação que trata do currículo educacional é ainda superficial, já que o conceito não recebe uma suficiente definição e exposição de seus fundamentos e princípios. Além disso, o currículo carece de uma abordagem histórica dos direitos humanos que indique sua construção progressiva e as personalidades que fizeram e fazem parte dessa construção (RODINO et al, 2016, p. 104107). O conceito de cidadania é muito nacionalizado, o que impede uma visão para além das fronteiras, o de entender ser humano como um todo. Ainda, estuda-se mais as normas dos direitos que as instituições que devem protegê-los e promover seu cultivo.

Com relação ao material didático, notou-se neles um significativo crescimento dos conteúdos de direitos humanos (RODINO et al, 2016, p. 110-111). Ao contrário do caso analisado acima, em que nos referimos ao currículo, os livros didáticos dão maior atenção à construção histórica dos direitos humanos, tratando também das personalidades que foram relevantes nessa construção. Porém, uma insuficiência desses materiais é que eles tendem a 
tratar dos problemas sociais sem abordá-los como fenômenos que constituem violação dos direitos humanos. Como é possível falar de Direitos Humanos sem mostrar como estes foram e são transgredidos?

A metodologia desses materiais, por sua parte, progrediu no sentido do pensamento crítico e autônomo, através da maior presença de exercícios que exigem a atividade do estudante. Segundo Rodino (2016, p. 118), observa-se progresso também quanto ao maior número de projetos para a otimização da convivência escolar, que expressa a preocupação com a formação em direitos e a convivência democrática, mas a formação de professores é a área que menos se desenvolveu no sentido da educação em direitos humanos. Essa formação, inicial ou continuada, ainda é muito negligente com a pedagogia em direitos humanos.

Agora que temos um panorama dos conceitos e cenários propostos ao longo dos pontos anteriores, podemos tratar do contexto específico das escolas da Fronteira Trinacional. Para tal, optamos por conhecer como os professores dessa região entendem, justificam e aplicam práticas relativas aos direitos humanos na escola.

\section{PESQUISA DE CAMPO}

Para concretizar os objetivos mencionados no início deste artigo, optamos por aplicar entrevistas a docentes do Ensino Básico que atuam na Tríplice Fronteira, guiados pelos cânones da pesquisa qualitativa. Dessa forma, além de dados que podem ser quantificáveis, buscamos significados e conteúdos dos conceitos e práticas relatadas pelos docentes em torno ao tema do nosso interesse. Como estes dados foram obtidos de primeira mão, provindos da fala das pessoas, favorecem uma leitura interpretativa (DEMO, 1995, p. 241).

Segundo Elliott (1997), para conhecer um problema no campo educacional o pesquisador está obrigado a valorizar a voz dos que guiam o processo de educação: os/as docentes. Em tal sentido, optamos pela elaboração e aplicação de uma entrevista semiestruturada como instrumento de pesquisa. Esta consiste na aplicação de questões previamente estabelecidas, mas com perguntas abertas que permitem ao entrevistado se expressar com liberdade, bem como ao pesquisador ampliar a discussão ou questionar para além das perguntas previstas (LAKATOS, 2003, p. 197). Em consequência, foram objeto das 
entrevistas professores e professoras das redes públicas que atendem alunos do Ensino Fundamental II: três brasileiros de Foz do Iguaçu, dois paraguaios de Ciudad del Este e dois argentinos de Puerto Iguazú.

A entrevista foi construída da seguinte forma: Um primeiro item para conhecer questões associadas à trajetória e condições laborais do entrevistado na rede pública do ensino. Um segundo item para compreender como o professor valoriza o sistema escolar em relação ao cultivo dos Direitos Humanos. Um terceiro item foi pensado para entender as percepções dos docentes sobre a educação em valores e cidadania. Um quarto e último teve por meta conhecer se os professores observam condutas, nos seus estudantes, que refletem alguns tipos de preconceitos étnicos, raciais ou de gênero.

\section{APRESENTAÇÃO DOS DADOS OBTIDOS NA PESQUISA DE CAMPO}

Os dados surgidos nas entrevistas foram ponderados a partir da análise geral de dados qualitativos, nos passos propostos por Bogdan e Biklen (1994, p. 221) e Creswell (2007, p. 195-199): digitalizar todo o material; ler detidamente toda a informação para fazer uma classificação geral e agrupar material ou ideias semelhantes; revisar a agrupação e estabelecer as primeiras conclusões; revisar novamente todo o processo anterior de modo a encontrar possíveis erros na interpretação ou observar novas ideias antes não consideradas; escrever o informe de análise a partir das conclusões, utilizando um estilo narrativodescritivo para apresentar os resultados e extraindo e fazendo compreensível o significado dos dados para todo tipo de leitor.

\section{- Sobre questões profissionais do(a) entrevistado(a).}

Constatamos que todos/as os/as entrevistados/as possuem mais de cinco anos em sala, e a grande maioria mais de cinco anos de experiência no ensino público. Isto é importante, pois se relaciona com a confiabilidade das respostas, além de conferir maior propriedade dos docentes para falarem de questões escolares sobre as quais possuem suficiente experiência.

Sobre o apoio governamental enquanto aos materiais pedagógicos e cursos de formação continuada do professorado, a grande maioria qualifica o apoio dos governos como "regular" ou "deficiente". Nesse sentido, podemos atribuir boa parte das insuficiências 
educacionais ao papel limitado dos governos (MARQUES et al, 2007 p. 12-13). Um número considerável dos entrevistados justificou o apoio limitado dos governos apontando para: a não gratuidade, generalismo e escassez dos materiais didáticos, bem como a insuficiência, baixa qualidade e inacessibilidade dos cursos de capacitação.

\section{- Sobre a valoração do sistema escolar e da educação em direitos humanos.}

Ainda como desdobramento do ponto anterior, procuramos obter uma avaliação da educação ofertada, de forma a verificar se essa tem correspondido aos desafios que a própria realidade educacional apresenta. $42,8 \%$ dos professores/as disseram que o ensino público é deficiente ou regular, enquanto $57 \%$ o consideram bom ou muito bom. Observa-se assim certa dificuldade em extrair conclusões através desses dados. Se o papel do Estado se mostrou limitado no ponto anterior, é razoável dizer que estes dados dizem respeito ao esforço individual dos/as docentes. Embora as políticas educacionais tenham muitas carências, pode ser que essas sejam compensadas (apenas em parte) pelo esforço diário dos/as docentes que fazem o impossível diante de condições não favoráveis.

Já tendo um panorama básico da experiência dos docentes entrevistados, começamos a indagar mais diretamente sobre o tema da nossa pesquisa, os DDHH, Valores e Cidadania. Perguntamos como eles percebem o comportamento ético entre os estudantes e entre estudantes e docentes. As respostas permitem observar uma relativa diferença: enquanto metade declara que entre estudantes a relação é "boa" ou "muito boa", a outra declara ser "regular" ou "deficiente"; e, entre professores e estudantes, as respostas transitam entre "regular", "boa" e "muito boa". Nas justificações ao panorama anterior percebe-se que aqueles que indicaram um cenário relativamente favorável o justificaram a partir da transversalidade, do diálogo, da empatia, da atuação de psicólogos e o apoio dos pais. Para aqueles que o cenário é desfavorável, a presença de preconceitos, o desrespeito entre estudantes e o autoritarismo na relação estudantes/docentes são as principais causas.

Logo, pretendíamos saber se o Plano Nacional de Educação em Direitos Humanos (que os três países da Fronteira possuem) é conhecido e incorporado à prática pedagógica. Uma maioria, ainda que não muito expressiva, não leram o documento. Outros, já o fizeram. Isto talvez possa confirmar o avanço da educação em direitos humanos em nossa região, já descrita anteriormente, mas que não está assegurada, em suas distintas dimensões. 
Posteriormente, procuramos conhecer sobre a natureza conceitual dos direitos humanos e a importância que o/a docente atribui no processo educativo. Desejávamos saber se o/a professor/a trazia uma noção conceitual do tema e se conferia importância a ele. Apenas a partir dessas condições seria capaz tornar a formação em direitos humanos parte relevante de sua prática pedagógica. De fato, os dados revelam que o entendimento sobre direitos humanos e sobre educação em direitos humanos é satisfatório, pois está em conexão com a teoria abordada na primeira parte deste artigo. No entanto, o problema é que apenas duas respostas indicaram a relevância desses conceitos.

Além do anterior, procuramos saber as preferências metodológicas dos docentes com relação ao cultivo dos direitos humanos. Sobressaíram as metodologias da transversalidade e das dinâmicas dialógicas, ambas entendidas como essenciais no processo de construção dos direitos humanos. Essas serão objeto de discussão maior abaixo, na articulação dos dados com a teoria.

No último momento deste ponto, nosso objetivo foi entender como os docentes convertem em práticas pedagógicas as concepções relativas aos Direitos Humanos. A partir das respostas, foi possível constatar a indicação de diversas atividades, sendo as mais nomeadas o debate sobre situações cotidianas, as atividades lúdicas e projetos na comunidade e no movimento estudantil.

\section{- Sobre a educação em valores e cidadania.}

A terceira parte da entrevista foi dedicada aos conceitos "valores" e "cidadania", temas que são essenciais nos direitos humanos. Pretendíamos, primeiramente, saber se os docentes haviam lido documentos oficiais de seus países a respeito da educação em valores e cidadania (eixo ético da educação presente no currículo dos três países da fronteira). As respostas são preocupantes, pois observamos que a maioria não leu tais documentos. Ou seja, claramente a atenção está mais concentrada em outros aspectos da educação.

Logo, solicitamos uma definição da educação em valores e cidadania. As respostas, ainda que diversas, favorecem entender que alguns professores definem a cidadania como "consciência dos direitos e deveres", enquanto outros apontaram os valores e cidadania como "fundamentais para a convivência em sociedade". Uma resposta complementa assinalando que "a cidadania deve ser crítica, e não apenas conformista". Se há um ponto em comum a todas as respostas, é que a maioria concebe "a cidadania como socialização do 
indivíduo às regras e normas sociais". E todos/as consideram que a dimensão ética da educação é o mais importante no processo formativo, justificando que a importância dos valores e cidadania se deve à sua relação com a coesão social e na relevância dessa formação para a luta pelos próprios direitos e mobilidade social.

Para conhecer em um nível mais concreto como os valores e cidadania são cultivados, perguntamos pelas práticas pedagógicas que eles realizam ou tem observado de outros docentes. Entre as respostas se destaca: atividades dialógicas, aplicação de projetos comunitários, atividades sobre o papel do negro na formação do Brasil e atividades que promovem prática de valores e a participação no movimento estudantil.

Insistindo para refletirem sobre as abordagens metodológicas e didáticas do assunto, queríamos saber de que forma entendem que é preferível trabalhar valores e cidadania. O resultado foi contundente: há uma preferência clara pelo diálogo. Mas também se observam respostas que defendem a transmissão de valores, a transversalidade ou aplicação de apostilas. As justificações dos dados anteriores fazem referência, principalmente: à importância do exemplo docente; o diálogo como forma de educar e tornar um conteúdo compreensível, para além de "engajar" aos estudantes.

\section{- Sobre questões específicas: preconceito e discriminação.}

Os objetos desta última parte da entrevista foram o preconceito e discriminação. Os direitos humanos, valores e cidadania possuem íntima relação com a busca por construir uma sociedade mais justa, solidária e inclusiva. Por esta razão, nossa ideia era saber se os preconceitos são manifestações frequentes na escola, mas não foi possível fazer uma asserção monocromática sobre a frequência de ocorrência dos preconceitos. Os dados mostram que em alguns contextos eles são "raros" enquanto em outros se apresentam de "forma regular". Mas o certo é que há preconceito, independente da frequência. O preconceito é sinônimo de dor em quem o experimenta, razão suficiente para considerá-lo.

$\mathrm{Na}$ justificação das respostas, encontramos que os preconceitos se manifestam através de piadas, indiferença, apelidos e agressão física em alguns casos. Mas o bullying e piadas que exploram estereótipos são as formas sob as quais esses preconceitos mais aparecem. Como exemplo, foi citado um caso de um aluno transexual, vítima da indiferença "piadinhas" dos colegas. 
Para ampliar ainda mais nossa compreensão, indagamos "a quem" ou "ao que" esses docentes atribuíam a causa dos preconceitos. Os dados são categóricos: a família em primeiro lugar, e em seguida a escola. Também foi mencionado o governo, a cultura patriarcal e xenofóbica, os meios de comunicação e o individualismo.

Finalmente, para verificar se os professores tinham em mãos ferramentas pedagógicas para enfrentar esse cenário, tratamos de inquirir sobre que atividades eles achavam que devem ser praticadas para trabalhar valores que não favoreçam, nos alunos e nas alunas, condutas de racismo, preconceito ou discriminação. As respostas nos permitem chegar à conclusão de que para os entrevistados a superação dos preconceitos depende, especialmente, de três fatores: favorecer o contato com diversos contextos sociais; formar a partir de hábitos; praticar o diálogo por meio de debates.

\section{ARTICULAÇÃO DADOS/TEORIA}

Como observamos, a primeira parte do questionário estabelece o perfil dos professores entrevistados. Como é possível perceber, a experiência dos docentes em sala de aula, e no ensino público, é suficiente para atribuir legitimidade aos dados. Pode-se dizer, então, que os dados dizem respeito, em grande parte, à realidade da educação pública experimentada profissionalmente pelos sujeitos.

A educação em direitos humanos, como política de Estado, é dependente da educação pública e não deve estar inteiramente submetida à iniciativa privada. $\mathrm{O}$ alcance da escola pública permite a concretização de um Plano Nacional de Direitos Humanos, com penetração ampla e profunda na sociedade. Além disso, a educação pública e gratuita garante o direito de todos à instrução, previsto pelo artigo XXVI da Declaração Universal dos Direitos Humanos (NAÇÕES UNIDAS, 2009, p. 14).

Percebemos que grande parte do apoio que o Estado oferece a esses professores é deficiente ou regular. E não nos referimos apenas à questão dos direitos humanos, mas à educação como um todo. Os professores justificaram esse cenário apontando que os materiais disponíveis aos professores são escassos, não gratuitos e generalistas, isto é, não consideram necessidades e problemas específicos dos contextos em que estão inseridas as escolas. Já os cursos ofertados foram descritos como "sem qualidade" e de difícil acesso.

No âmbito da cultura escolar, sobre o convívio entre os estudantes e entre estudantes e professores, aqueles professores que se mostraram satisfeitos com a condição 
de sua escola apontaram a transversalidade da ética, o diálogo, a empatia, a atuação de psicólogos e o apoio dos pais como elementos que sustentam essa boa condição. Já para os professores para quem a situação é "regular" ou "deficiente", as causas elencadas foram a presença de preconceitos, o desrespeito entre estudantes e o autoritarismo na relação estudantes/docentes.

Verificamos que quase a metade dos professores não leram os documentos oficiais de seus respectivos países sobre educação em direitos humanos. É verdade que o documento não deve orientar apenas as ações dos professores, mas de forma mais ampla, de políticas educacionais, instituições e sociedade civil como um todo. No entanto, o engajamento e a integração de cada professor nesse esforço nacional e internacional são de suma importância. De modo que, o que conseguimos auferir aqui é esse nível de engajamento.

Com relação à definição de direitos humanos, podemos perceber que todas as respostas trazem uma noção conceitual relativamente satisfatória. Seja como proteção da pessoa humana, como conjunto de compromissos com cada um que a sociedade deve satisfazer, ou como direitos inerentes ao ser humano, cada resposta apresentou um aspecto da definição de direitos humanos. Com Peñailillo e Kant (2009 e 2011) vimos como a atribuição de legitimação ao outro e a dignidade são centrais para a definição de direitos humanos. Outro ponto essencial, como consta na DUDH, é a inerência desses direitos ao ser humano, "sem distinção de qualquer espécie, seja de raça, cor, sexo, idioma, religião, opinião política ou de outra natureza, origem nacional ou social, riqueza, nascimento, ou qualquer outra condição" (NAÇÕES UNIDAS, 2009, p. 5).

A educação em direitos humanos foi definida como a etapa da concretização desses direitos, como promoção de trabalhos pedagógicos sobre eles, como transmissão de valores, como orientação sobre direitos e deveres e, por fim, como conjunto de normas. Apenas duas respostas apresentaram a justificativa da importância desses conceitos. Essas foram a remissão da intolerância na sociedade e a busca por maior coesão social.

Vimos, também, como os direitos humanos favorecem essa coesão, ao constituir um ponto pacífico na diversidade de interesses dos grupos e indivíduos. No entanto, o índice de justificação sobre a relevância desses conceitos é pequeno, e isso nos alerta para o risco da limitação retórica e da falta de prática no cotidiano escolar. A capacidade de atribuir razões é um dos pilares da motivação íntima para colocar em prática um conjunto de ideias. 
Sobre as metodologias "ideais" para o cultivo dos direitos humanos sobressaem o ensino transversal e as dinâmicas dialógicas. O ensino transversal tem uma base teórica muito interessante, pois, como pensa Araújo (2003), consiste basicamente em que os professores/as ajustem temáticas ou problemas sociais aos conteúdos específicos de cada disciplina. Mas como notamos na seção em que tratamos do cenário da educação em direitos humanos na América Latina, a transversalidade pode ser uma forma de dissolver a obrigatoriedade do tema e impedir o implemento de disciplinas específicas. Ao constituir responsabilidade de todos os professores e na ausência de uma disciplina específica, correse o risco dos direitos humanos ficarem esquecidos e perderem espaço para os conteúdos específicos, a prioridade de sempre dos professores. A transversalidade é essencial, mas pode coexistir com disciplinas específicas sobre direitos humanos para a garantia plena de sua abordagem.

Com essa ressalva, podemos então reconhecer o caráter essencial do ensino transversal, uma vez que a educação da moralidade, que abarcam conceitos como valores e cidadania, pode ser tomada como a finalidade da própria educação (CRISTI; MARTíN, 2018, p. 10). Os conteúdos e disciplinas específicas são "meios" e existem em função dos objetivos da formação em valores e para a cidadania (ARAÚJO, 2008, p. 1995). Já as dinâmicas dialógicas são centrais para a visão construtivista, em que os alunos não apenas reproduzem, mas criam ideias, ações, e são coautores do conhecimento e de sua própria identidade (ARAÚJO, 2008, p. 194). Além disso, segundo a ONU, os métodos participativos são um dos princípios da educação em direitos humanos. Através deles é que o ambiente se torna propício ao desenvolvimento da liberdade de expressão e pensamento, dois dos direitos presentes na DUDH.

Sobre as metodologias propostas pelos docentes, destaca-se o debate sobre situações cotidianas. Este é importante, pois a promoção da análise de problemas sociais e da pertinência dos direitos humanos na vida cotidiana do estudante são princípios estabelecidos pelo Programa Mundial de Educação em Direitos Humanos. Debates sobre o desemprego, a fome, a crise habitacional e a falta de saneamento básico, podem funcionar como um ensejo ao conhecimento e valorização do direito ao trabalho, à alimentação, à moradia e à saúde, todos propostos na DUDH.

Já a aplicação de projetos na comunidade, ou entre os próprios estudantes, também trabalham esses princípios do Programa Mundial, além de dar a conhecer os "mecanismos de proteção aos direitos humanos". Araújo (2008, p. 1998) sugere ainda que 
os projetos são a concretização pedagógica do construtivismo. Um contexto adequado à análise e síntese de informações, planejamento de ações, resolução de problemas e criação de novas ideias, processos que tornam o estudante um sujeito ativo no seu aprendizado.

O cenário da compreensão dos professores sobre a definição da cidadania estabelece esse conceito como consciência dos direitos e deveres e os valores como fundamentais para a convivência em sociedade. Mas um professor aponta a importância da cidadania crítica e não conformista. Afinal, cidadania pode ser compreendida não apenas como consciência de direitos e deveres, mas como engajamento e participação na própria construção e contínua reformulação desses direitos e deveres.

Outro aspecto do debate é pensarmos em cidadania como estatuto político. Desse modo, o conceito está intimamente vinculado a uma ordem jurídica capaz de resguardar a proteção dos indivíduos (LOBATO; PEIXOTO, 2013, p. 52). Assim passamos do dever do indivíduo para o dever da comunidade, da humanidade. $\mathrm{O}$ indivíduo deve cumprir com certos preceitos para se adequar à uma vida social, mas em contrapartida, a comunidade como um todo deve garantir a proteção dos indivíduos. Esse estatuto permite o acesso e participação no espaço público (LOBATO; PEIXOTO, 2013, p. 53).

Em síntese, a conceituação de cidadania dos docentes se mostra relativamente limitada ao engajamento às normas, uma etapa importante da formação, mas que sozinha não favorece o desenvolvimento de sujeitos críticos e autônomos. Concepção mais ampla é pensarmos em cidadania como participação ativa e, ainda, como proteção jurídica garantida pela comunidade. Educar para a cidadania é "proveer a los individuos de instrumentos para la plena realización de esta participación motivada y competente, de esta simbiosis entre intereses personales y sociales, de esta disposición para sentir los dolores del mundo" (MACHADO, apud AHUMADA e MARTIN, 2018, p. 6).

A educação em valores e cidadania foi considerada, por todos os professores, o aspecto mais importante da educação. O que parece justificar que esses temas tenham um lugar privilegiado na educação por meio do ensino transversal. As respostas foram fundamentadas em dois eixos. Primeiro, na importância da formação em valores e cidadania para a coesão social. Segundo, na relevância dessa formação para a luta pelos próprios direitos e pela mobilidade social.

A seguir, novamente perguntamos por aquelas práticas pedagógicas que os docentes observaram ou aplicaram, mas agora tendo em vista os valores éticos e a 
cidadania. Apareceram mais uma vez os projetos comunitários, que já comentamos. Outra professora realizou uma atividade sobre o papel do negro na formação do Brasil. Em seguida os estudantes produziram revistas sobre o assunto.

Essa atividade é um excelente exemplo de educação em valores, porque permite o contato e a valorização de grupos historicamente vítimas de segregação. A valorização da diversidade é um dos focos centrais nessa dimensão da educação. Nesse sentido, outro projeto interessante que aqui destacamos promovia práticas relacionadas à algum valor específico. Visitas em hospitais, como relatado, podem ser ótimas oportunidades para trabalhar a empatia. Por último, na esteira de uma sugestão docente, a cidadania pode ser desenvolvida por meio do incentivo à participação no movimento estudantil.

Ações como essa satisfazem o aspecto da construção dos valores que diz respeito à formação de hábitos. Há ainda, pelo menos, mais duas dessas dimensões da educação moral. Essas são a cognitiva e a afetiva. A primeira requer a capacidade de justificar condutas ou opiniões morais. A segunda depende da capacidade compreensiva de adaptar o juízo moral às situações concretas e particulares (PUIG, 1995, p. 115).

Sobre as opções pedagógicas que os professores achavam mais adequadas ao cultivo dos valores e cidadania, como vimos, os métodos dialógicos e a transversalidade se destacaram. Outro dos aspectos que foi considerado é a educação de hábitos, ou, no sentido clássico, das virtudes. É preciso que os estudantes desenvolvam práticas virtuosas cotidianamente. Para isso, o ambiente escolar deve oferecer modelos pessoais dos valores que se busca promover, e no seu dia a dia, as práticas desejadas devem possuir presença constante (PUIG, 1995, p. 110).

O diálogo, a principal escolha dos docentes aqui, nos remete à possibilidade de desenvolver valores a partir da construção dialógica da personalidade moral. Tem lugar aqui a promoção das controvérsias e conflitos morais, que geram crises cognitivas e demandam sua solução por parte do estudante (PUIG, p. 113, 1995).

Quando se trata de cidadania, o diálogo mais uma vez é imprescindível. Se falar em cidadania, em poucas palavras, é falar de participação, então o diálogo talvez seja a primeira oportunidade para estimular a expressão e o posicionamento (AHUMADA e MARTIN, 2018). Além disso, o trabalho com as mídias é especialmente relevante para a cidadania, como afirmou um professor que as indicou como importantes para a criticidade. Ainda nesse sentido, o trabalho com jornais e revistas permite despertar interesse em questões políticas e sociais. 
Na terceira parte das entrevistas identificamos que o bullying e a indiferença são as principais manifestações de discriminação. A família em primeiro lugar, e em seguida a escola, governo, a cultura patriarcal e xenofóbica, os meios de comunicação e o individualismo foram elencados como principais causas. As formas de superação da vigência do racismo, preconceitos e discriminação, segundo os próprios professores, depende de favorecer o contato com diversos contextos sociais, a formação de hábitos e os debates. A compreensão da particularidade de cada indivíduo é uma boa opção para lidar com preconceitos e discriminação, uma vez que os preconceitos se caracterizam por uma generalização categórica sobre um indivíduo ou determinado grupo (PINHEIRO, 2011, p. 216). Pinheiro indica a necessidade da educação como forma de gerar a consciência dos mecanismos do funcionamento do preconceito, auxiliando com que os educandos o identifiquem em si e nos outros.

\section{CONSIDERAÇÕES FINAIS}

Como estabelecemos na apresentação, tínhamos à vista conhecer as formas e as razões pelas quais a educação em Direitos Humanos, valores e cidadania é cultivada nas escolas da Fronteira Trinacional. Ainda que umas poucas questões específicas ficaram inconclusivas, como aquela relativa à avaliação do ensino público e a outra em que perguntamos sobre a frequência da ocorrência dos preconceitos em sala, todas as demais revelam dados claros e generalizáveis. Por conta dessa unidade, pudemos construir o cenário geral que buscávamos e que apresentamos de maneira conclusiva a seguir.

Como já é recorrente na literatura que trata de questões educacionais no Brasil, Argentina e Paraguai, o apoio do Estado foi mais uma vez caracterizado como insuficiente, tanto em termos de materiais didáticos como de cursos de capacitação. Talvez por isso percebeu-se também um pequeno nível de engajamento dos professores ao Plano Nacional de Direitos Humanos.

O convívio entre os diversos atores das escolas mostrou-se marcado por preconceitos, desrespeito e autoritarismo, mas também pelo diálogo e empatia. O que torna inviável uma única conclusão a respeito da qualidade desse convívio. No entanto, cabe alertar para a presença dos preconceitos, uma forma de violência simbólica capaz de estigmatizar, traumatizar e gerar transtornos psicológicos. 
Por outro lado, os docentes apresentaram uma compreensão conceitual adequada da definição de direitos humanos e das metodologias ideais para o seu cultivo, mas a maioria não justificou a importância da educação em direitos humanos. Embora entendam os conceitos de forma teórica, e ainda que considerem os temas transversais o aspecto mais importante da educação, os docentes parecem não conseguir fundamentar essa opinião.

Quanto à materialização dessa compreensão teórica por meio de atividades pedagógicas, a maioria não especificou práticas relacionadas, lançando mão de certos "generalismos" em suas respostas. Isto é, tais respostas não traziam um nível mínimo de aprofundamento, com alguns detalhes adjacentes, e se limitavam a afirmações como "fazemos atividades com filmes".

Ainda assim, boa parte dos docentes citaram atividades muito relevantes à construção dos direitos humanos, as quais já analisamos acima. São propostas recomendadas inclusive por estudiosos da educação em direitos humanos que atestam o excelente grau de preparo e comprometimento de muitos professores que entrevistamos. Seria enorme injustiça não reconhecer e valorizar esses casos.

Apesar de considerarem a educação em valores e cidadania o aspecto mais importante da educação, ou um dos mais importantes, a educação para a cidadania é mais entendida como adaptação às normas ao invés de participação ativa que leva à transformações sociais. Aderir às normas valorizadas socialmente é um passo importante na construção do sujeito, mas por si só não garante a formação de sujeitos participativos. Ainda assim, todas as práticas pedagógicas descritas apresentaram pertinência e relevância para o tema. O mesmo podemos dizer das preferências metodológicas dos professores, transversais, dialógicas e a partir do exemplo.

Por último, desejamos comentar que estamos cientes que esta pesquisa não esgota, de modo nenhum, a compreensão da situação dos direitos humanos nas escolas da Fronteira Trinacional. Ainda assim, confiamos que a percepção que os docentes possuem da educação em Direitos Humanos, valores e cidadania refletem certas realidades em torno desses conceitos nos sistemas escolares. Isto já é um avanço, e talvez um impulso para outras pesquisas mais específicas, por exemplo, sobre a situação do preconceito e bullying nas escolas da região fronteiriça. 


\section{REFERÊNCIAS}

ARAÚJO, U. F. Pedagogia de Projetos e Direitos Humanos: Caminhos para uma Educação em Valores. Pro-Posições; v. 19, n. 2 (56) - maio/ago; 2008.

ARAÚJO, U. Temas transversais e a estratégia de projetos. São Paulo: Moderna, 2003.

BERLIN, I. Dois Conceitos de Liberdade. Tradução Aline Mesquita. Universidade Federal do ABC. Disponível em: https://docs.google.com/file/d/OB-ZLHzAcvfuUMGFhYldLQjFzemc/edit; Acesso em 19/08/2018.

BOBBIO, N. A Era dos Direitos. Tradução Carlos Nelson Coutinho; Apresentação de Celso Lafer: Rio de Janeiro: Elsevier, 2004.

BOGDAN, R.; BIKLEN, S. Investigação Qualitativa em Educação: Uma introdução à teoria e aos métodos. Porto Editora, 1994.

CASADO FILHO, N. Direitos Humanos e Fundamentais. São Paulo - SP: Saraiva, 2012.

CRISTI, M. A.; MARTíN, X. Educación Moral en Sudamérica: Un Sistema Pedagógico de Transversalidad. Revista Brasileira de Educação; vol. 23, 2018.

DEMO, P. Metodologia Científica em Ciências Sociais. 3a Ed: São Paulo: Atlas, 1995.

ELLIOTT, J. La Investigación Acción en Educación. España: Morata, 1997.

FRAGA, G. W.; MAHLKE, H. A Operação Condor e os Direitos Humanos na América Latina. Diálogo; no 16, jan-jun 2010, p.89/105.

KANT, Immanuel. Fundamentação da Metafísica dos Costumes. Tradução de Paulo Quintela: Lisboa - Portugal: Edições 70 LDA, 2011.

LAKATOS, E. M. Fundamentos de Metodologia Científica. 5a Ed: São Paulo: Atlas: 2003.

LOBATO, A. O. C; PEIXOTO, C. C. Pensar a Cidadania em Hannah Arendt: Direitos a ter Direitos; Direitos Sociais Fundamentais: Contributo Interdisciplinar para a Redefinição das Garantias de Efetividade / Organizadores Josirene Candido Londero e Carlos André Hüning Birnfeld - Rio Grande: Editora da FURG, 2013.

MARQUES, E. P. et al. Educação Pública: Falta de Prioridade do Poder Público ou Desinteresse da Sociedade? Rev. Bras. Crescimento Desenvolv. Hum; 17(3), 2007. p. 08-20.

MILLAS, J., Fundamentos de los Derechos Humanos. Revista Análisis. Santiago de Chile, 1982.

NAÇÕES UNIDAS. Declaração Universal dos Direitos Humanos. Janeiro de 2009. Disponível em: https://nacoesunidas.org/wp-content/uploads/2018/10/DUDH.pdf; Acesso em: 28/07/2020. 
NAÇÕES UNIDAS. Proyecto Revisado del Plan de Acción para la Primera Etapa (2005-2007) del Programa Mundial para la Educación en Derechos Humanos. 2 de março de 2005. Disponível

em: https://www.ohchr.org/EN/Issues/Education/Training/WPHRE/FirstPhase/Pages/planaction. aspx; Acesso em 11/07/2020.

NODARI, P. C.; SÍVERES, L. Dos Direitos Naturais aos Direitos Humanos e a Dignidade Humana; Conjectura: Filos. Educ. Caxias do Sul, v. 20, n. especial, 2015. p. 263-280.

PEÑAILILLO, P. La Razón de Ser de los Derechos Humanos. La Perspectiva de Jorge Millas: Campeador que Rompe Todas sus Lanzas y Destroza el Corazón en la Batalla. Sociedad Chilena de Filosofía Jurídica y Social. Valparaíso; no 27, 2009. p. 301-311.

PINHEIRO, V. P. G. Preconceito, Moralidade e Educação Moral para a Diversidade. Revista Brasileira de Educação; v. 16, n. 46, jan.|abr. 2011.

PUIG, J. M. Construcción Dialógica de la Personalidad Moral. Revista lberoamericana de Educación. № 8, 1995. págs. 103-120.

RODINO, A. M.; TOSI, G.; FERNÁNDES, M. B.; ZENAIDE, M. N. T. Cultura e Educação em Direitos Humanos na América Latina. João Pessoa: Editora do CCTA, 2016.

Recebido em 04 de setembro de 2020. 